\title{
Assessment of process configurations to combine enantioselective chromatography with enzymatic racemization
}

\author{
Isabel Harriehausen ${ }^{1} \cdot$ Katarzyna Wrzosek $^{1} \cdot$ Heike Lorenz $^{1} \cdot$ Andreas Seidel-Morgenstern $^{1}$
}

Received: 8 October 2019 / Revised: 31 March 2020 / Accepted: 3 April 2020 / Published online: 7 May 2020

(c) The Author(s) 2020

\begin{abstract}
Enantioselective chromatography is nowadays a reliable tool for single enantiomer production from a racemate. The recovery of the distomer by racemization and recycling is a promising method to tackle the $50 \%$ yield constraint and to increase the productivity. In this paper three process configurations are compared. The production of enantiopure mandelic acid and methionine enantiomers exploiting different enzymes for racemization are evaluated as part of different chromatographic process configurations. First, the benefits of conventional simulated moving bed (SMB) chromatography in contrast to a single column batch separation unit are assessed in integrated configurations. Then, a concept of coupling the racemization with a simpler three-zone SMB unit, where one regeneration zone is removed, is evaluated.
\end{abstract}

Keywords Chiral separation · Batch chromatography $\cdot$ SMB processes · Enzymatic racemization · Distomer recovery Process integration

\section{Introduction}

For the provision of pharmaceutical ingredients or in the food and agrochemical industries, the production of pure enantiomers is crucial. Even though chiral synthesis by fermentation is well established, e.g. for production of the essential amino acids, this pathway is not always available or requires a long reaction chain. In these cases, the racemic approach of an unselective synthesis with a subsequent separation and recycling of the distomer is becoming an attractive alternative (Francotte 2001). The separation can be done e.g. by enantioselective chromatography or preferential crystallization (Lorenz and Seidel-Morgenstern 2014). For enantioselective chromatography there are versatile and highly selective but costly chiral stationary phases available (Franco et al. 2001).

A desirable exploitation of the distomer after separation can be done in connection with racemization. Such reactions can be realized under extreme $\mathrm{pH}$ or temperature conditions and/or catalyzed chemically or enzymatically (MartínMatute and Bäckvall 2007). Besides enhancing the reaction

Isabel Harriehausen

harriehausen@mpi-magdeburg.mpg.de

1 Max-Planck-Institut fur Dynamik komplexer technischer Systeme, Sandtorstr. 1, 39106 Magdeburg, Germany rate, enzymatic racemization allows the operation under mild process conditions. Despite their large potential, the amount of available racemases is still limited (Würges et al. 2009; Radkov and Moe 2013; Femmer et al. 2016). When immobilized on a resin and packed in a fixed bed reactor, enzymes can show high stability and no extra enzyme recovery step is needed (Wrzosek et al. 2018). Since the driving force for racemization is the enantiomeric excess and concentration of the distomer, for optimal process performance the enzymatic reactor can be positioned in the recycling stream between the distomer outlet of a suitable separation unit and the feed tank to recover the target enantiomer. This way, the yield could be increased from 50 up to $100 \%$. In order to further improve the productivity, other processes can be integrated to increase solution concentrations. Disadvantages of e.g. filtration are possible compound loss and therefore yield reductions, and/or high energy demands in case of applying evaporation.

The main objective of this work is the introduction of a new process configuration in which a continuously operated simulated moving bed (SMB) chromatography unit, which consists conventionally of four characteristic separation zones, is simplified into a three zone (3Z) SMB unit and connected to a recycling loop with a chemical or enzymatic fixed bed racemization reactor. These setups will be 
compared theoretically based on standard key performance indicators.

Below, we will firstly provide a short summary of similar coupled system. Then, three analyzed chromatography configurations are introduced. Next, the mass balances of chromatographic columns and assumptions regarding the jointly quantified racemization and recycling steps are presented. The hypothetical limiting case of a true moving bed process (TMB) and the established corresponding triangle theory is applied to explain the possible transition from the conventional four-zone to the promising simpler three-zone SMB process. In Sect. 6, the two model systems considered are introduced. Section 7 presents simulation results for the comparison of alternative coupled processes with the standard 4Z-SMB unit. Here they are also used to evaluate the influence of the case specific characteristics of the processed enantiomers. Finally, the strength of three zone SMB process is highlighted.

\section{Background}

Integration of chromatographic separation with reaction steps was discussed by e.g. Hashimoto et al. (1983) and used to increase yield and productivity for producing a targeted sugar. Based on this idea, a number of approaches involving combinations of separation and reaction types for enrichment of high and low value products of different purities were studied by Bechtold et al. (2006) and Palacios et al. (2011). The process configurations investigated had different degrees of integration and complexity. Coupled systems were studied theoretically (von Langermann et al.

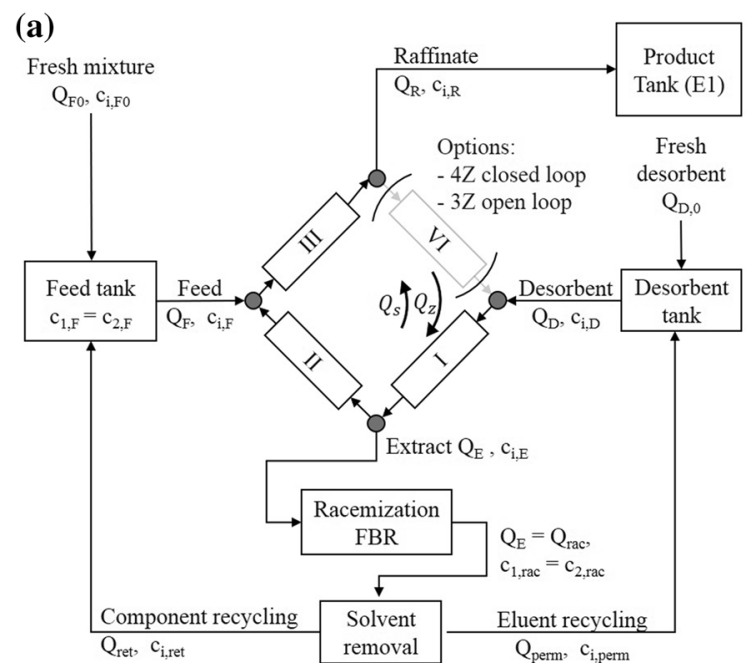

Fig. 1 Coupling of a SMB unit integrated with an enzymatic fixed bed racemization reactor (EFBR) and a solvent removal (SR) unit. The SMB unit is shown both as a 4Z closed-loop and a 3Z open-loop process. After separation in setup (a) the raffinate and in setup (b) the
2012; Nimmig and Kaspereit 2013; Swernath et al. 2014) and were implemented experimentally for the production of D-Psicose (Wagner et al. 2011). Additionally, a combination of chromatographic SMB separation and enzymatic racemization was used by Fuereder et al. (2016) for the production of pure methionine enantiomers. Results of a reevaluation of this study will be given in Sect. 7 .

In classical four zone close-loop (4Z) SMB chromatography each zone has a specific task (Broughton and Gerhold 1961). The zones II and III perform the separation of the binary system by carrying the less retained enantiomer to the raffinate port and the more retained enantiomer to the extract port. The first zone regenerates the stationary phase and the fourth zone regenerates the eluent. An alternative SMB process is the three zone (3Z) SMB, in which the fourth zone is omitted. When operating it in an open-loop configuration, the column number can be reduced without compromising throughput or product purity in exchange for an increased solvent consumption. This is an attractive approach for systems with an expensive stationary phase and a relatively cheap mobile phase (Paredes et al. 2004; Sreedhar and Kawajiri 2014).

\section{System configurations}

In this study, three chromatographic separation unit types were investigated each combined with racemization. The simplest concept considers a single separation column operated in the conventional batch mode as analyzed in Wrzosek et al. (2018). The two other setups are based on the SMB principle and presented schematically in Fig. 1.

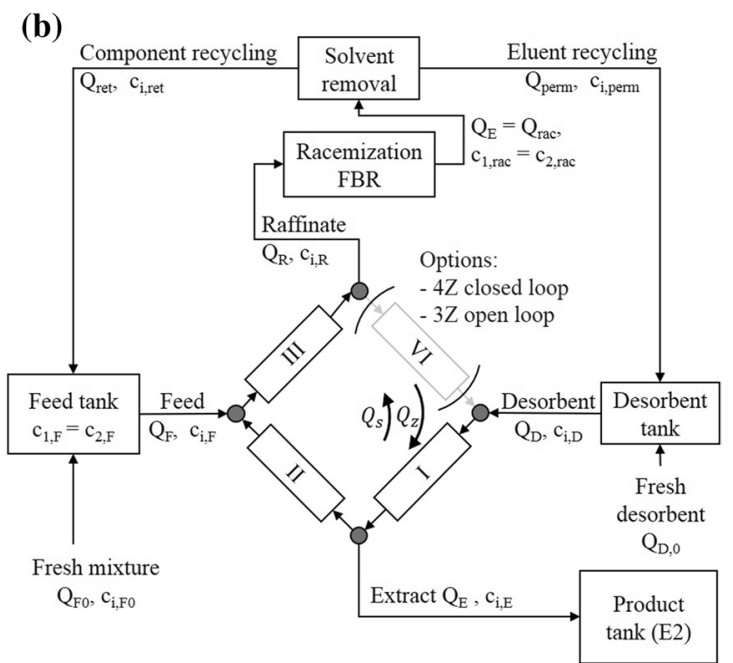

extract contain the target enantiomer. The distomer is racemized in the EFBR and concentrated in the SR unit before recycling it back to the feed tank 
Depending of the specific target molecule, either the less retained enantiomer E1 is collected at the raffinate port (Fig. 1a) or the more retained enantiomer E2 at the extract port (Fig. 1b). The other outlet stream, enriched in the distomer, is recycled. This recovery is performed using two additional process units. First, the distomer is racemized in a fixed bed reactor filled e.g. with an immobilized racemase ( Wrzosek et al. 2016).

For the sake of simplicity and to focus on the central chromatographic separation unit, this reactor was modeled with an infinite residence time and therefore assuming a complete racemization $\left(c_{1, r a c}=c_{2, \text { rac }}\right)$. This desired situation can be reached by installing a sufficiently large racemization reactor. A recycling step using a solvent removal unit was included to increase the concentration of the generated racemate. Depending on the specific molecular weights of solvents and solutes this could either e.g. be a nanofiltration or an evaporation unit.

\section{Process model}

The coupled chromatography-racemization process was studied theoretically. In this chapter, the mass balances of the process units, the essential adsorption isotherms and the performance criteria considered are introduced.

\subsection{Mass balance of a separation column}

The equations to describe the separation unit are based on the mass balances for a chromatographic column (SchmidtTraub et al. 2012):

$\frac{\partial c_{i}}{\partial t}+F_{\mathrm{c}} \cdot \frac{\partial q_{i}\left(c_{1 \ldots \mathrm{N}}\right)}{\partial t}+u_{\mathrm{c}} \frac{\partial\left(c_{i}\right)}{\partial x}=D_{\text {app }} \frac{\partial^{2} c_{i}}{\partial x^{2}}$

with $c_{i}$ being the concentration and $q_{i}=f\left(c_{1} \ldots c_{\mathrm{N}}\right)$ being the loading of the component $i=1, \ldots, N$ where $N$ is the number of components. Furthermore, the time and space variables are noted as $t$ and $x$, respectively, and $u_{c}$ is the interstitial linear velocity. The phase ratio $F_{c}$ of the column is defined in Eq. (2) by the porosity $\epsilon_{t, \mathrm{c}}$ of the stationary phase as a ratio of the solid and void phase.

$F_{\mathrm{c}}=\frac{1-\epsilon_{t, \mathrm{c}}}{\epsilon_{t, \mathrm{c}}}$

The apparent dispersion $D_{\text {app }}$ lumps contributions of e.g. axial dispersion and mass transfer resistances. It can be modeled by numerical dispersion with the corresponding height of an equivalent theoretical plate (HETP).
$H E T P=\frac{L_{c}}{N_{p}}$

$D_{\text {app }}=\frac{u_{\mathrm{c}} \cdot H E T P}{2}$

Here, $L_{\mathrm{c}}$ is the length and $N_{\mathrm{p}}$ is the plate number of a chromatographic column.

The initial conditions of fully regenerated columns are

$c_{i}(t=0, x)=0$

The boundary condition

$c_{i}(t, x=0)=c_{\text {in,system }}(t)$

depends on the chosen chromatographic system. For a single batch column setup with rectangular pulse injections of a concentration $c_{i, \mathrm{~F}}$, the inlet stream $c_{\mathrm{in} \text {, batch }}(t)$ is defined as

$c_{\text {in, batch }}(t)= \begin{cases}c_{i, \mathrm{~F}}, & 0+\Delta t_{\mathrm{i}, \mathrm{cyc}}(k-1)<t \\ t<\Delta t_{\text {inj }}+\Delta t_{\mathrm{i}, \mathrm{cyc}}(k-1) & \\ 0, \quad \text { else }\end{cases}$

with the feed concentration $c_{i, \mathrm{~F}}$ and a cycle time $\Delta t_{i, \mathrm{cyc}}$, i.e. the time difference between two consecutive injections $(k-1)$ and $k$ with $k=1, \ldots, N_{\text {cyc }}$. The batch chromatography process was evaluated based on averaged inlet stream concentrations

$\bar{c}_{i, \mathrm{~F}}=\frac{c_{i, \mathrm{~F}} \cdot V_{i, \mathrm{inj}}}{Q_{\mathrm{z}} \cdot \Delta t_{i, \mathrm{cyc}}}$

with the injection volume $V_{i, \text { inj }}$.

In SMB chromatography the feed is introduced continuously onto the first column between the second and third zone and all other columns are fed with the outlets of the prior column

$c_{\mathrm{in}, \mathrm{SMB}}(t)=\left\{\begin{array}{l}c_{i, \mathrm{III}}(t, x=0)=c_{i, F} \\ c_{i,(z \neq \mathrm{III})}(t, x=0)=c_{i,(z \neq \mathrm{III})-\mathrm{I}}\left(t, x=\mathrm{L}_{\mathrm{c}}\right)\end{array}\right.$

\subsection{Adsorption isotherms}

In order to describe the specific, and for the separation essential adsorption equilibria $q_{i}\left(c_{1}, \ldots, c_{\mathrm{N}}\right)$, three adsorption isotherm (AI) models are introduced. The easiest form is the linear adsorption isotherm:

$q_{i}=K_{i} \cdot c_{i} \quad i=[1,2]$

A quadratic isotherm model 
$q_{i}=q_{\mathrm{s}} \frac{c_{i} \cdot\left(b_{i, 1}+2 \cdot b_{i, 2} \cdot c_{i}\right)}{1+b_{i, 1} \cdot c_{i}+b_{i, 2} \cdot c_{i}^{2}} \quad i=[1,2]$

can be used for describing the equilibria of compounds with a fronting behaviour, also referred to as anti-Langmuir. Here, $q_{s}$ is the saturation capacity, $K_{i}, b_{i, 1}$ and $b_{i, 2}$ are quantifying adsorption isotherm coefficients. The thermodynamically consistent explicit solution of the competitive isotherm for single component AI according to Eq. (11) has been developed by Ilić et al. (2010).

A very common model, capable to describe adsorption behaviour, is the dual site competitive bi-Langmuir model:

$$
\begin{aligned}
q_{i}= & q_{\mathrm{s}, 1} \frac{b_{1, i} \cdot c_{i}}{1+b_{1,1} \cdot c_{1}+b_{1,2} \cdot c_{2}} \\
& +q_{\mathrm{s}, 2} \frac{b_{2, i} \cdot c_{i}}{1+b_{2,1} \cdot c_{1}+b_{2,2} \cdot c_{2}} \quad i=[1,2]
\end{aligned}
$$

The selectivity of the stationary phase for enantioseparation $\alpha_{\mathrm{c}}$ can be estimated as the ratio of the initial slopes of the two enantiomer isotherms $\left(\approx K_{i}\right)$

$\alpha_{c}=\frac{K_{2}}{K_{1}}$

\subsection{Counter current chromatography (TMB and SMB)}

A well established approach to estimate the SMB performance is the true moving bed (TMB) model (Broughton and Gerhold 1961). Here, the standard chromatography mass balance equation (Eq. (1)) is expanded by a term quantifying countercurrent movement of the stationary phase.

$\frac{\partial c_{i}}{\partial t}+F \cdot \frac{\partial q_{i}\left(c_{1 \ldots \mathrm{N}}\right)}{\partial t}+u_{c} \frac{\partial c_{i}}{\partial x}-F \cdot u_{\mathrm{s}} \frac{\partial q_{i}\left(c_{1 \ldots \mathrm{N}}\right)}{\partial x}=0$

Of particular interest is the steady state solution of the TMB process which forms, after spacial discretization, a large system of nonlinear algebraic equations. It is a well established procedure to solve the dynamic equations until the final steady state, which is the operating state of interest, is reached. This approach was also used for all other units considered in the overall process schemes.

In a TMB unit the volumetric flow rates $Q_{z}$ in each zone $(z=\mathrm{I}, \ldots, \mathrm{IV})$ are connected with the external flow rates for desorbent, extract, feed and raffinate, respectively

$Q_{\text {ext }}=\left[-Q_{\mathrm{D}}, Q_{\mathrm{E}},-Q_{\mathrm{F}}, Q_{\mathrm{R}}\right]$

It holds that

$Q_{\mathrm{I}}=Q_{\mathrm{D}}+Q_{\mathrm{IV}}$
$Q_{\mathrm{II}}=Q_{\mathrm{I}}-Q_{\mathrm{E}}$

$Q_{\mathrm{III}}=Q_{\mathrm{II}}+Q_{\mathrm{F}}$

$Q_{\mathrm{IV}}=Q_{\mathrm{III}}+Q_{\mathrm{R}}$

To generate enantiopure solutions at the raffinate and extract port, the flow rates in each zone need to be properly set. They can be described in a normalized form as dimensionless flow rate ratios $m_{z}$

$m_{\mathrm{z}}=\frac{Q_{\mathrm{z}}}{Q_{\mathrm{s}}}$

with $Q_{\mathrm{s}}$ being the volumetric flow rate of the solid phase. By exploiting the equilibrium theory of chromatography, regions for the flow rates can be derived, which allow a successful binary separation and a regeneration of the stationary and mobile phases (Rodrigues 2015). For linear isotherms it holds that:

$K_{1}<m_{\mathrm{II}}<m_{\mathrm{III}}<K_{2}$

$m_{\mathrm{I}}>K_{2}$

$m_{\mathrm{IV}}<K_{1}$

The region for linear isotherms in which both enantiomers elute with $100 \%$ purity is triangular and plotted in the $m_{\mathrm{II}}$ - $m_{\mathrm{III}}$-plane. Its shape and magnitude are visualized in Fig. 2.

When only one enantiomer is targeted, the constraint on the distomer becomes obsolete, which reduces Eqs. (21) to (24) or (25) if the purity constraint regarding the raffinate or extract, respectively, is removed.

$m_{\mathrm{II}}<m_{\mathrm{III}}<K_{2}$

$K_{1}<m_{\mathrm{II}}<m_{\mathrm{III}}$

With the constraint in Eq. (23) the solvent can be regenerated in the last zone to reduce its consumption. In a closedloop SMB operation, a removal of this zone would cause a contamination of the extract. In a $3 \mathrm{Z}$ open-loop operation, the zone is omitted in trade-off for a higher dilution of the raffinate stream and higher solvent consumption. The 3Z-SMB system can then be described by Eqs. (22) and (24) or (25).

\subsection{Incorporation of the racemization reactor}

The degree of conversion of the recycled stream into a racemate of the chromatographic unit is directly related to the reaction rate and the scale of the reaction unit. Hence, with sufficient amount of enzyme a full racemization can be 


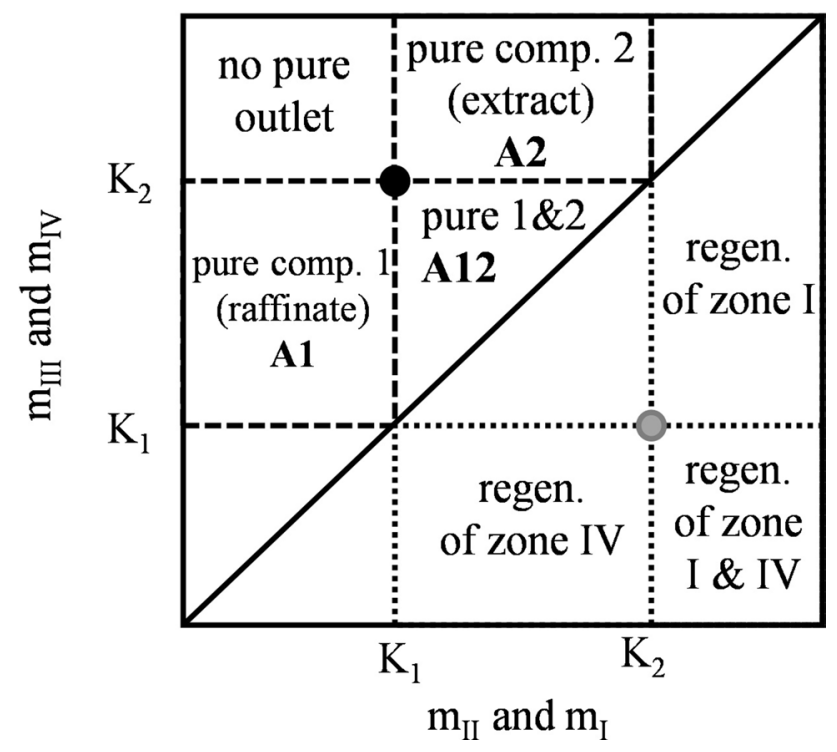

Fig. 2 Triangle theory according to equilibrium theory of TMB chromatography for linear adsorption behaviour in accordance to Eqs. (21)-(23) (Mazzotti et al. 1997). The optimal separation condition for $m_{\mathrm{II}}$ and $m_{\mathrm{III}}$ is in the upper left corner of the separation region (black circle), the optimal regeneration condition for $m_{\mathrm{I}}$ and $m_{\mathrm{IV}}$ in the corresponding corner of the regeneration region (grey circle)

performed. In order to analyze the maximum of this effect, in the scope of this paper the achievement of a complete conversion of any effluent mixture into a 50:50 mixture was assumed. This simplifies the dynamic mass balance equation of the reaction unit

$\frac{\partial c_{i, \text { reactor }}}{\partial t}+u_{z} \frac{\partial c_{i}}{\partial z}+F_{\text {rac }} v_{i} r_{\text {reactor }}=0$

with

$c_{\text {tot }}=c_{1}+c_{2}$

to

$c_{i, \text { reactor }}=\frac{c_{1, \text { rec }}+c_{2, \text { rec }}}{2}$

Here $Q_{\mathrm{rec}}$ is the volumetric flow rate of the recycled extract $Q_{\mathrm{E}}$ or raffinate $Q_{\mathrm{R}}$ stream and $v_{i}$ is the stoichiometric coefficient with $v_{1}=-1$ for E1 and $v_{2}=+1$ for E2.

\subsection{Modeling of the solvent removal unit}

To capture essential features of the entire flowsheet, two additional balances must be respected (Fig. 1). The solvent removal unit is positioned behind the racemization unit and treated as a simple splitter unit. It divides the stream into the permeate flow rate $Q_{\text {perm }}$, that can be recycled to the eluent tank, and the retenate volumetric flow rate $Q_{\text {ret }}$, which has a racemic composition and is recycled to the feed tank.

$Q_{\text {rec }}=Q_{\text {perm }}+Q_{\text {ret }}$

Depending on the capabilities of the concentration unit and the application specific requirements, the separation factor

$\alpha_{\mathrm{SR}}=\frac{Q_{\text {perm }}}{Q_{\text {ret }}}$

needs to be adjusted. The recovery rate of the solvent removal unit is defined as the ratio of the recovered total mass flux $\dot{m}_{\text {tot,ret }}$ (with $\dot{m}_{\text {tot }}=\dot{m}_{1}+\dot{m}_{2}$ ) and the mass flux from the racemization reactor into the solvent removal unit $\dot{m}_{\text {tot,reactor }}$

$R E C_{\mathrm{SR}}=\frac{\dot{m}_{\mathrm{tot}, \mathrm{ret}}}{\dot{m}_{\text {tot,reactor }}}=\frac{Q_{\mathrm{ret}} \cdot c_{\mathrm{tot}, \text { ret }}}{Q_{\mathrm{rec}} \cdot c_{\mathrm{tot}, \text { reactor }}}$

and depends on the chosen process.

The following mass balances hold for the solvent removal unit:

$\frac{\partial c_{i, \text { ret }}}{\partial t}=\frac{1}{V_{\mathrm{SR}}}\left(R E C_{\mathrm{SR}} \cdot Q_{\mathrm{rec}} \cdot c_{i, \text { reactor }}-Q_{\mathrm{ret}} \cdot c_{i, \text { ret }}\right)$

$\begin{aligned} \frac{\partial c_{i, \text { perm }}}{\partial t}= & \frac{1}{V_{\mathrm{SR}}}\left(\left(1-R E C_{\mathrm{SR}}\right) \cdot Q_{\mathrm{rec}} \cdot c_{i, \text { reactor }}\right. \\ & \left.-Q_{\mathrm{perm}} \cdot c_{i, \mathrm{perm}}\right)\end{aligned}$

In this work, the separation factor $\alpha_{\mathrm{SR}}$ was linked to the total mass flux at the reactor outlet to maintain a constant concentration $c_{\text {tot, } \mathrm{F}}=c_{1, \mathrm{~F}}+c_{2, \mathrm{~F}}$ and a racemic composition in the feed tank. A full recovery $\left(R E C_{\mathrm{SR}}=1\right)$ was assumed.

\subsection{Modeling of the feed and desorbent tanks}

To capture essential features of the whole flowsheet, two additional balances must be respected (see Fig. 1). The amount of fresh feed is regulated by the feed flow rate $Q_{\mathrm{F}}$ out of the feed tank and the recycled retenate flow $Q_{\text {ret }}$ :

$Q_{\mathrm{F} 0}=Q_{\mathrm{F}}-Q_{\text {ret }}$

The following mass balance equation is applied for the feed tank

$\frac{\partial c_{i, \mathrm{~F}}}{\partial t}=\frac{1}{V_{\text {tank } \mathrm{F}}}\left(Q_{\mathrm{F}} \cdot\left(c_{i, \mathrm{ret}}-c_{i, \mathrm{~F} 0}\right)-Q_{\mathrm{ret}} \cdot\left(c_{i, \mathrm{~F} 0}-c_{i, \mathrm{~F}}\right)\right)$

Due to the solvent removal unit, only the difference of the inlet desorbent stream $Q_{\mathrm{D}}$ and the recovered solvent $Q_{\text {perm }}$ is required as fresh solvent $Q_{\mathrm{D} 0}$ 
$Q_{\mathrm{D} 0}=Q_{\mathrm{D}}-Q_{\mathrm{perm}}$

The fresh solvent contains obviously no solute

$c_{i, \mathrm{D} 0}(t)=0$

which reduces the mass balance equation of the solvent tank to

$\frac{\partial c_{i, \mathrm{D}}}{\partial t}=\frac{1}{V_{\text {tank }, \mathrm{D}}}\left(Q_{\mathrm{perm}} \cdot c_{i, \mathrm{perm}}-Q_{\mathrm{D}} \cdot c_{i, \mathrm{D}}\right)$

\subsection{Model implementation}

The solutions of the described dynamic model of the setup, including a TMB model for the SMB unit, were implemented with Python (Python 3.6, Rossum, CWI, Netherlands). Below we will analyze just the steady state solutions obtained after integrating the dynamic equations sufficiently long. An automatic detection of the steady state situation at the product outlet terminated the integration.

\section{Process evaluation}

The evaluation and performance of the process options depend on the elution order of the two enantiomers, which is given by the selectivity of the used chromatographic system. When targeting the first eluting enantiomer E1 (target $=1)$, the product stream of a SMB unit is collected at the raffinate port

$\dot{m}_{1}=Q_{\mathrm{R}} \cdot c_{1, \mathrm{R}}$

and when targeting the more retained E2, the extract elutes into the product tank (target $=2$ )

$\dot{m}_{2}=Q_{\mathrm{E}} \cdot c_{2, \mathrm{E}}$

\subsection{Productivity, solvent consumption and yield}

For process evaluation of the coupled process, the purity of the target enantiomer (Eq. (41)) needs to be fixed.

$P U R_{\text {target }}=\frac{c_{\text {target }}}{c_{1}+c_{2}} \cdot 100 \%$

In this work a target purity of $99.5 \%$ was considered. The distomer purity was no criterion for optimization, as it was recycled in the enzymatic fixed bed reactor and therefore only affected the productivity by indirectly reducing the intrinsic feed (Eqs. (39), (40)).

As representative parameters for economic efficiency, productivity (Eq. (43)) and solvent consumption (Eq. (44)) were chosen. The productivity is given in terms of collected mass stream per volume of stationary phase of the chromatographic system, as the latter is a decisive factor in the process economy. Here, $N_{\text {col }}$ is the number of columns applied

$P R_{\text {target }}^{*}=\frac{\dot{m}_{\text {target }}}{N_{\mathrm{col}} \cdot V_{\mathrm{c}} \cdot\left(1-\epsilon_{\mathrm{t}, \mathrm{c}}\right)}$

Alternatively a mass related productivity is often used, where the solvent density is estimated from the typical density of silica gels $\left(\delta_{c}=2.6 \mathrm{~g} / \mathrm{cm}^{3}\right)$

$P R_{\text {target }}=\frac{\dot{m}_{\text {target }}}{N_{\mathrm{col}} \cdot V_{c} \cdot\left(1-\epsilon_{\mathrm{t}, \mathrm{c}}\right) \cdot \delta_{\mathrm{c}}}$

The solvent consumption $\left(S C_{i}\right)$ is the ratio of the required fresh desorbent and the mass flux at the target outlet.

$S C_{\text {target }}=\frac{Q_{\mathrm{D} 0}}{\dot{m}_{\text {target }}}$

Main benefit of the process integration investigated here is the enhanced overall yield, which is defined in Eq. (45). While yield can theoretically reach $100 \%$, a possible incomplete recovery (Eq. (31)) of the substance in the solvent removal unit leads to lower values. In this case yield can be determined with Eq. (46).

$Y_{\text {target }}=\frac{\dot{m}_{\text {target }}}{Q_{\mathrm{F} 0} \cdot\left(c_{1, \mathrm{~F} 0}+c_{2, \mathrm{~F} 0}\right)}$

$Y_{\text {target }}=1-\frac{\left(1-R E C_{\mathrm{SR}}\right) \cdot Q_{\mathrm{rec}} \cdot c_{\mathrm{tot}, \mathrm{rec}}}{Q_{\mathrm{F} 0} \cdot c_{\mathrm{tot}, \mathrm{F} 0}}$

\subsection{Identifying favorable operating SMB conditions}

In preliminary experiments the adsorption behaviour of mandelic acid (case study 1) in an SMB unit was analyzed. This was done with a simple algorithm which found the trajectory of the operating conditions for $99.5 \%$ enantiopure E1 and E2. Based on the results the coupled process was designed. Now, for a broader overview of the separation in the SMB unit, the $m_{\mathrm{II}}-m_{\mathrm{III}}$-area was scanned with a small grid size. The flow rates $m_{\mathrm{I}}$ and $m_{\mathrm{IV}}$ were fixed based on information from the preliminary trajectory. In each point the process performance of the steady state was evaluated based on Eqs. (43)-(45). As a results the most productive flow rate conditions could be identified. 


\section{Two case studies}

The success of a process not only depends on its setup, but also on the specific characteristics of the chiral substances and the chromatographic system used for resolution. In this paper, the production of pure enantiomers for mandelic acid and methionine are analyzed and compared. With this study of two different model systems, specific influences can be illustrated.

\subsection{Case study 1: Mandelic acid enantiomers}

The first set of simulations in this paper is based on preliminary work published in Wrzosek et al. (2018). Both the 4Z- and 3Z-SMB concepts, as well as the single column batch chromatography are evaluated based on the published adsorption parameters for the two mandelic acid enantiomers. When being separated in a Chirobiotic T column (250 $\mathrm{mm} \times 4.6 \mathrm{~mm}$ ID, $5 \mu \mathrm{m}$ ) with an aqueous mobile phase (with $20 \% \mathrm{MeOH}, 20 \mathrm{mM}$ HEPES, $3.3 \mathrm{mM} \mathrm{MgCl}_{2}$ at $\mathrm{pH}$ 6.8), the less retained $(S)$-form shows a rare anti-Langmuir behaviour, while the isotherm of the more retained $(R)$-form is almost linear. Thus, the two species were modelled with Eqs. (11) and (10), respectively. Essential parameters of this system

Table 1 Case study 1 specific data of the batch separation process (Wrzosek et al. 2018) and assumptions for the other process units

\begin{tabular}{llll}
\hline Parameter & Symbol & Value & Unit \\
\hline Fresh feed conc. & $c_{i, \mathrm{~F} 0}$ & $2,7.5,20$ & $(\mathrm{~g} / \mathrm{L})$ \\
Chromatographic separation & & & \\
Quadratic AI & $q_{\mathrm{s}}$ & 4.7 & $(\mathrm{~g} / \mathrm{L})$ \\
(Eq. (11)) & $b_{1}$ & 0.060 & $(\mathrm{~g} / \mathrm{L})$ \\
& $b_{2}$ & 0.0137 & $(\mathrm{~g} / \mathrm{L})$ \\
& $H_{1}$ & 0.282 & $(\mathrm{~g} / \mathrm{L})$ \\
Linear (Eq. (10)) & $H_{i}$ & 0.6938 & $(-)$ \\
Column length & $L_{\mathrm{c}}$ & 150 & $(\mathrm{~mm})$ \\
Column porosity & $\epsilon_{\mathrm{t}, \mathrm{c}}$ & $0.65 / 0.61$ & $(-)$ \\
C. plate number & $N_{\mathrm{p}}$ & 100 & $(-)$ \\
Selectivity & $\alpha_{\mathrm{c}}$ & 2.44 & $(-)$ \\
Batch chromatography & & & \\
Flow rate & $Q_{\mathrm{batch}}$ & 0.5 & $(\mathrm{~mL} / \mathrm{min})$ \\
Cycle time E1 & $\Delta t_{1, \mathrm{cyc}}$ & 3.55 & $(\mathrm{~min})$ \\
Cycle time E2 & $\Delta t_{2, \mathrm{cyc}}$ & 4.62 & $(\mathrm{~min})$ \\
TMB chromatography & & & $(-)$ \\
Solid phase flow rate & $Q_{\mathrm{s}}$ & 1 & $(-)$ \\
Racemization reactor & & & $(\mathrm{mL} / \mathrm{min})$ \\
Reaction rate & $r_{\text {reactor }, i}$ & inf $(\mathrm{Eq} .(28))$ & $\left(\mathrm{min} / \mathrm{m}^{3}\right)$ \\
Solvent removal unit & & & \\
Split ratio & $\alpha_{\mathrm{SR}}$ & Adj. & $(1$ \\
Recovery rate & $R E C_{\mathrm{SC}}$ & 1 & \\
\hline
\end{tabular}

are summarized in Table 1. Subsequently, the simulation results based on the mandelic acid enantiomers will be referred to as case study 1 (CS1).

\subsection{Case study 2: Methionine enantiomers}

The processing of methionine enantiomers, in order to obtain pure D- or L-methionine, serves as a second case study (CS2). Parameters and process evaluation data were published by Fuereder et al. (2016). Their setup consisted of a 1-2-1-1 SMB unit and the racemization was carried out in an enzymatic membrane reactor with soluble racemase. A nanofiltration unit increased the concentration of the recycled stream. The adsorption isotherms of the methionine enantiomers on a Chirobiotic TAG column $(250 \mathrm{~nm} \times 4.6$ $\mathrm{nm}$ ID, $5 \mu \mathrm{m}$ ) revealed a dual Langmuir behaviour with two binding sides on the chiral phase (Eq. (12)). Despite having a similar selectivity of $\alpha_{\mathrm{c}, \mathrm{CS} 2}=2.58$ as the mandelic acid enantiomers (CS1), the adsorption equilibrium behaviour is characterized by different trends.

Figure 3 displays the single component adsorption isotherms of the mandelic acid enantiomers (CS1, sold line) in contrast to the methionine enantiomers (CS2, dashed line). The less retained enantiomer E1 is marked in red, the stronger retained enantiomer $\mathrm{E} 2$ in blue.

\section{Results and discussion}

As a reference, the separation regions and the performance of closed-loop four zone (4Z) simulated moving bed (SMB) chromatography were analysed for the classical process, considering the mandelic acid enantiomers (CS1) characterized by the quadratic isotherm model for enantiomer E1. Then, the process variant integrated with racemization was evaluated. Subsequently, a comparative assessment with

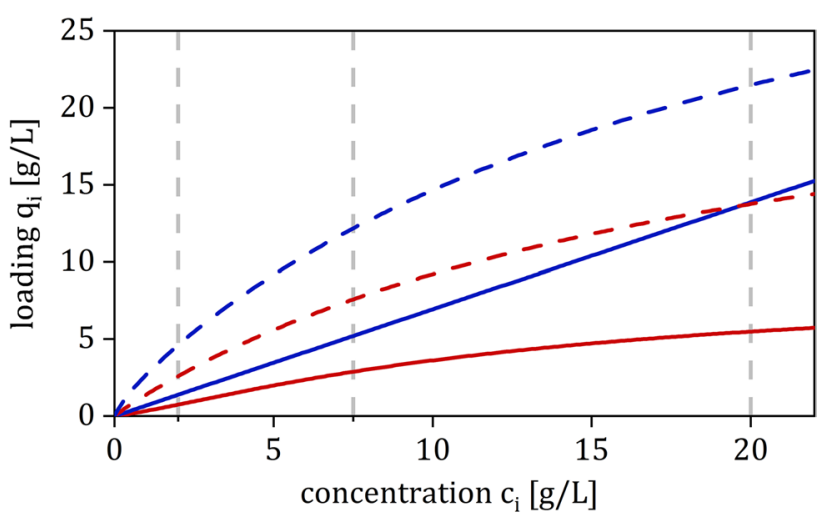

Fig. 3 Single component adsorption isotherms. Mandelic acid enantiomers (CS1, solid lines, Wrzosek et al. 2018) and methionine enantiomers (CS2, dashed lines, Fuereder et al. 2014) 
single column batch chromatography was made, followed by integrated $4 Z-S M B$ separation of methionine as second chiral system (CS2). The latter comparison evaluates the process performance as a function of selectivity of the chromatographic separation and solubility limits. Finally, the integrated open-loop three zone (3Z) SMB coupled with racemization, which to the best of our knowledge has not yet been reported, was investigated and compared to the more complex conventional 4Z-SMB configuration.

\subsection{Operational region for stand-alone 4Z-SMB}

Initially, an analysis and simulation of the conventional 4Z-SMB process was performed for producing pure enantiomers of CS1, exploiting the described TMB model and the parameters listed in Table 1. In applying the described scanning procedure to identify the size and shape of the separation region, the single component isotherms of the two enantiomers were used instead of the implicit multi-component adsorption isotherm models, which would have caused large computation times. This was considered to be justified because preliminary equilibrium calculations revealed rather low competition effects for this system.

Figure 4 shows the resulting separation regions of the conventional SMB unit in the $m_{\mathrm{II}}-m_{\mathrm{III}}$-separation region for three different racemic feed concentrations $c_{i, \mathrm{~F}}=1,2$, $7.5 \mathrm{~g} / \mathrm{L}$ for $\mathrm{i}=[1,2]$ (i.e. a total feed concentrations of $c_{\mathrm{tot}, \mathrm{F}}$ $=2,4,15 \mathrm{~g} / \mathrm{L}$ ). This region was calculated, fulfilling the requirements of complete regeneration, by choosing sufficiently safe $m_{\mathrm{I}}$ and $m_{\mathrm{IV}}$-values. In comparison to the corresponding separation regions for linear adsorption behaviour (Fig. 2), the anti-Langmuiran behaviour, characterizing the less retained enantiomer E1 in CS1, leads to a characteristic transformation of the shape of the region. This deformation strength is concentration dependent and the resulting shape of the separation region is oppositely curved to the wellknown distortion of Langmurian systems (Mazzotti et al. (1997)).

\subsection{Z-SMB chromatography with integrated racemization (CS1)}

A process configuration with racemization and recycling of the distomer stream brings two advantages. The distomer racemization increases the overall yield, because the target compound eluting at the wrong port is recycled. Therefore, the purity constraint of this outlet is of less importance. This results in new degrees of freedom for the operation of the SMB unit and expands the operating windows for the production of E1 (or E2), i.e. the area A1 (or A2) as shown in Fig. 4. Hence, depending on the target compound, the flow rate in zone II can be lowered for the collection of E1 at the raffinate port or the flow in zone III can be increased for the

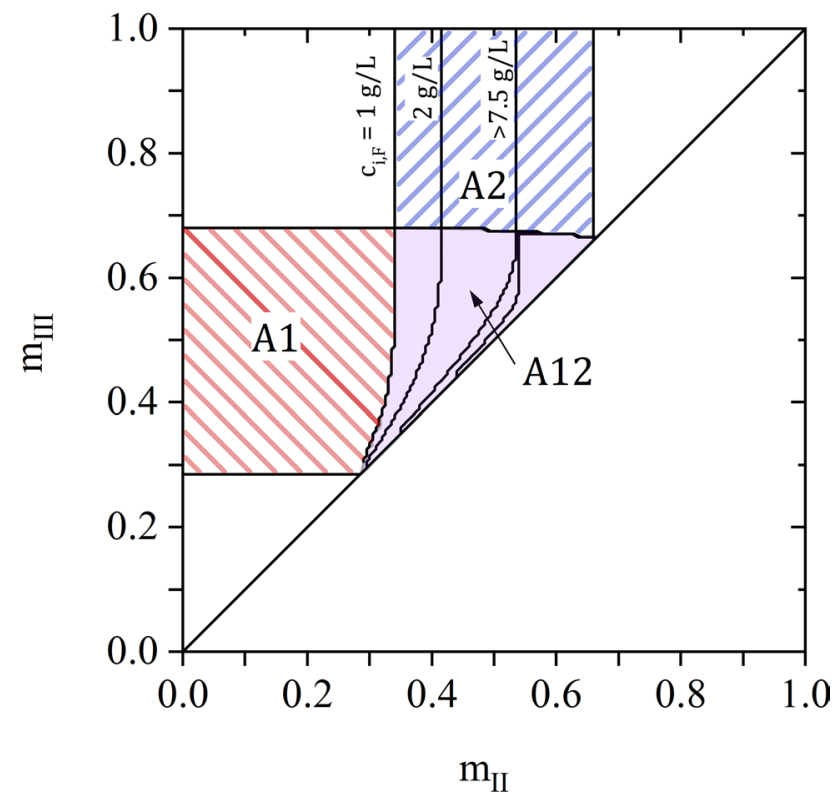

Fig. 4 Operating windows for a single 4Z-SMB unit with a $99.5 \%$ purity constraint at the raffinate and extract port for CS1 and the feed concentrations $c_{1, \mathrm{~F} 0}=c_{2, \mathrm{~F}}=1,2,7.5 \mathrm{~g} / \mathrm{L}$. The deviation in comparison to the results given for linear isotherms in Fig. 2 are due to the anti-Langmuir behaviour (Eq. (11))

collection of E2 at the extract port. In any case, the feed flow rate $Q_{\mathrm{F}}=Q_{\mathrm{III}}-Q_{\mathrm{II}}$ can be increased to obtain a higher throughput (Eq. (43)) compared to conventional operation. These trends are illustrated in Fig. 5 for the two different outlets and three chosen feed concentrations. The calculations revealed in the colour code for each operating point the corresponding achievable productivities.

For these simulations the $m_{\mathrm{II}}-m_{\mathrm{III}}$ plane was scanned using fixed flow rate ratios with $m_{\mathrm{I}}=0.8$ close to the theoretical limit of complete regeneration of the solid phase. The choice of the fixed phase ratio $m_{\mathrm{IV}}=0.3$ violates the purity constraint of Eq. (23), by slightly exceeding the low Henry coefficient of E1 $\left(H_{1}=0.282\right)$. This leads to a decrease in purity of $\mathrm{E} 2$ under diluted conditions $\left(P U R_{2}=99.5 \%\right.$ for $c_{\mathrm{i}, \mathrm{F}}$ $=2 \mathrm{~g} / \mathrm{L}$ ). For higher feed concentrations this contamination effect decreases due to the anti-Langmurian behaviour.

The productivities in region A1 for raffinate (E1) purification and A2 for extract (E2) purification vary significantly (Fig. 5). For each process, the operational point with the highest productivity of and lowest solvent consumption (within a safety margin of the boarders of the separation region) is marked with an asterisk and listed in Table 2. For a racemic feed concentration of $c_{i, \mathrm{~F}}=7.5 \mathrm{~g} / \mathrm{L}$ the productivity of $\mathrm{E} 2$ reaches a maximum of $75 \mathrm{~g} / \mathrm{kg} /$ day, exceeding the productivity of E1 $(58 \mathrm{~g} / \mathrm{kg} /$ day $)$. In particular, for the highest feed concentration of $c_{i, \mathrm{~F}}=20 \mathrm{~g} / \mathrm{L}$, the operating point offering the highest productivity for the production of E1 (indicated in Fig. $5 \mathrm{c}$ ) shifts towards smaller $m_{\mathrm{II}}$ values, 

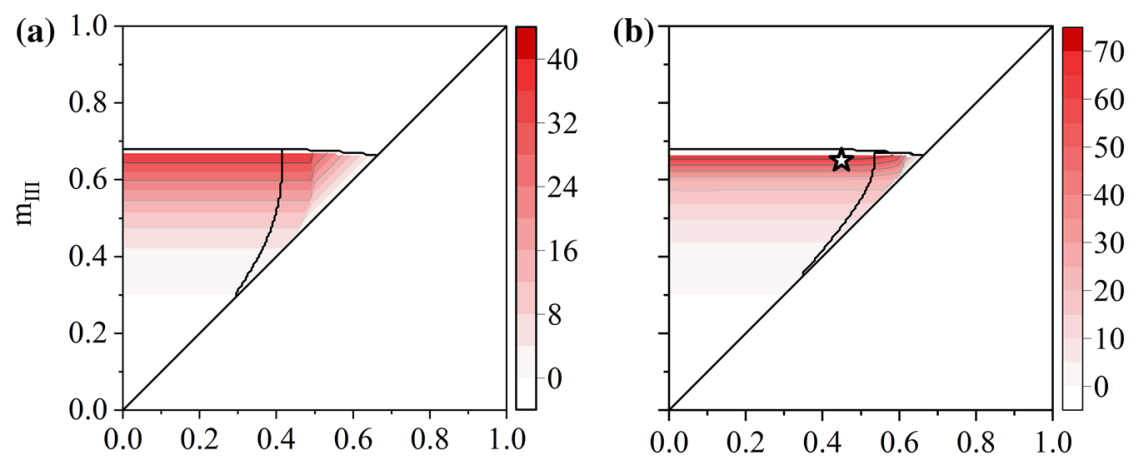

(c)
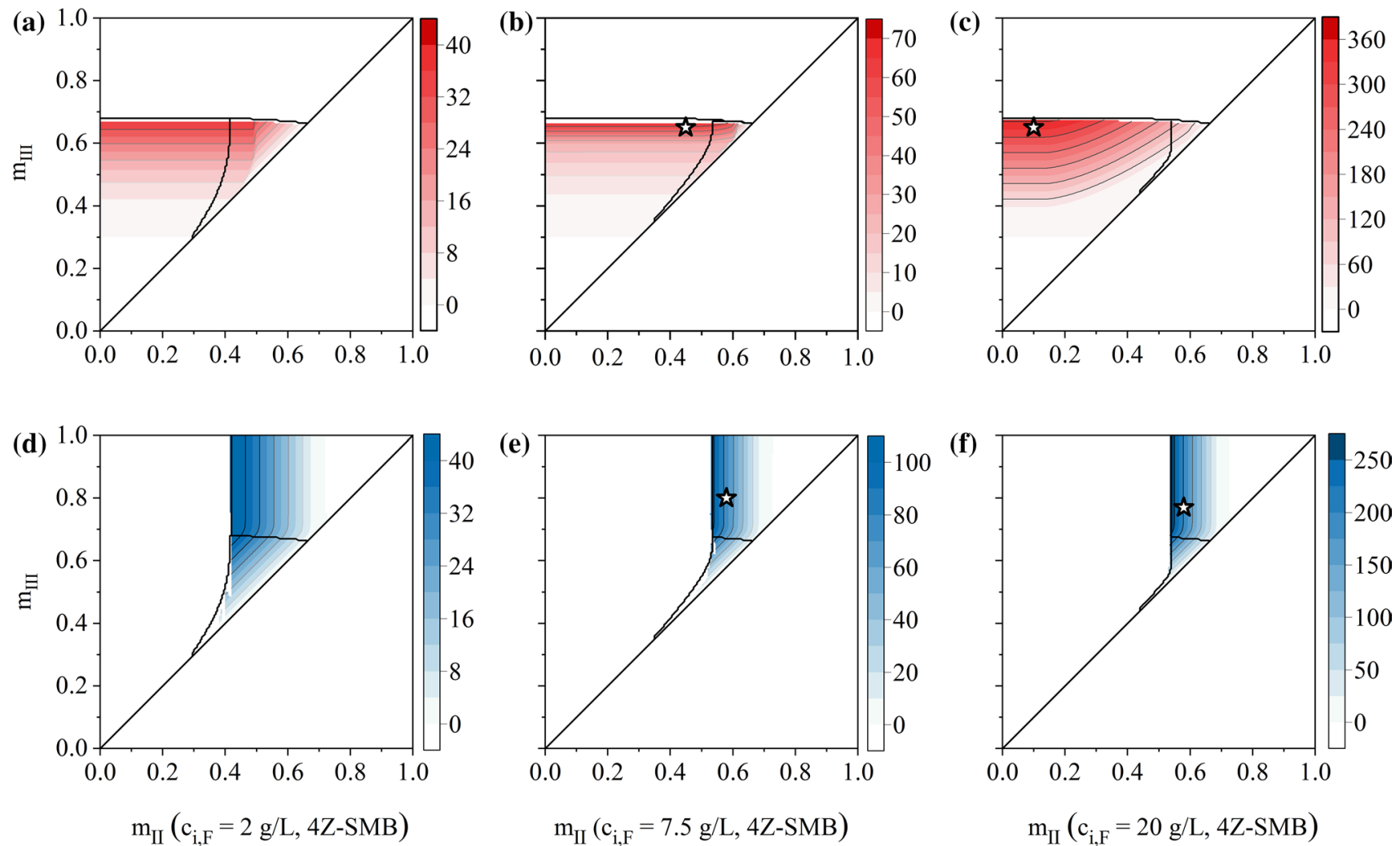

(e)

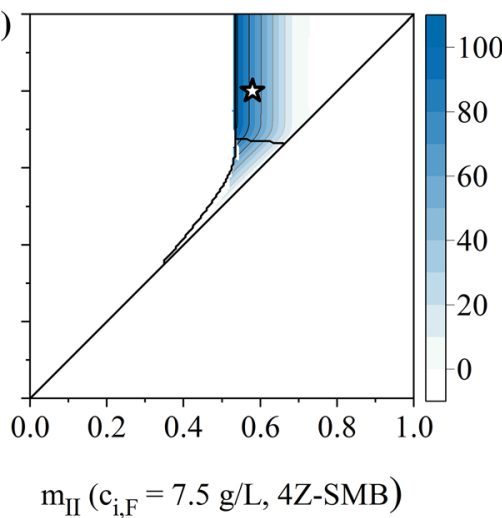

(f)

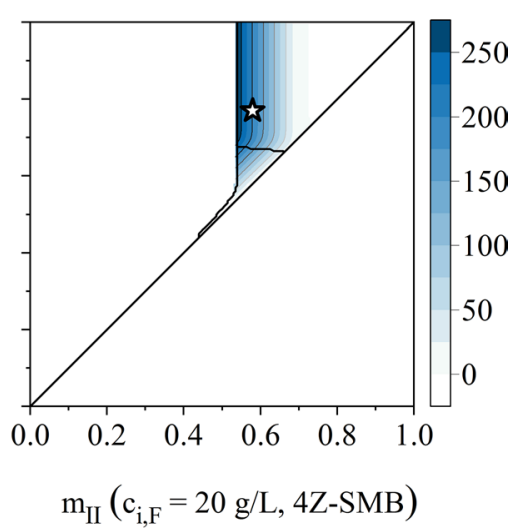

Fig. 5 Color-coded productivity in $\mathrm{g} / \mathrm{kg} /$ day of the coupled process for E1 and E2 of CS1 within the separation zones A1 and A2, respectively $\left(P U R_{\text {target }}=99.5 \%\right.$, Fig. 4$)$. The separation unit was operated in a closed-loop 4Z-TMB with fresh feed concentrations of $c_{i, \mathrm{~F}}=2$,
7.5 and $20 \mathrm{~g} / \mathrm{L}$ for a conventional closed-loop 4Z-TMB with flow rates of the regeneration zone of $m_{\mathrm{I}}=0.8$ and $m_{\mathrm{IV}}=0.3$. a-c: regions of pure raffinate, $\mathbf{d}-\mathbf{f}$ regions of pure extract. Asterisked points are marked in Figs. 6, 7, 9 and 10
Table 2 Overview of optimal process configurations at $99.5 \%$ target purity

\begin{tabular}{|c|c|c|c|c|c|c|c|c|c|}
\hline \multirow[t]{2}{*}{ CS } & \multirow[t]{2}{*}{ Process mode } & \multirow[t]{2}{*}{$c_{i, F}$} & \multirow[t]{2}{*}{$m_{\mathrm{II}}$} & \multirow[t]{2}{*}{$m_{\mathrm{III}}$} & \multicolumn{2}{|c|}{ Target } & \multirow{2}{*}{$\begin{array}{l}P R_{i} \\
\left(\frac{g}{k g \cdot d a y}\right)\end{array}$} & \multirow{2}{*}{$\begin{array}{l}S C_{i} \\
\left(\frac{L}{k g}\right)\end{array}$} & \multirow{2}{*}{$\begin{array}{l}P U R_{i} \\
(\%)\end{array}$} \\
\hline & & & & & Raff. & Extr. & & & \\
\hline \multirow[t]{2}{*}{1} & \multirow[t]{2}{*}{ Batch Chrom. ${ }^{a}$} & 20 & - & - & $\mathrm{x}$ & & 208.7 & 887.5 & 99.50 \\
\hline & & 20 & - & - & & $\mathrm{x}$ & 161.1 & 1150.0 & 99.50 \\
\hline \multirow[t]{4}{*}{1} & \multirow[t]{4}{*}{ 4Z-SMB } & 7.5 & 0.45 & 0.65 & $\mathrm{x}$ & & 57.5 & 464.7 & $>99.95$ \\
\hline & & 7.5 & 0.58 & 0.80 & & $\mathrm{x}$ & 74.5 & 195.5 & $>99.90$ \\
\hline & & 20 & 0.10 & 0.65 & $\mathrm{x}$ & & 485.5 & 38.0 & $>99.95$ \\
\hline & & 20 & 0.58 & 0.77 & & $\mathrm{x}$ & 198.6 & 72.3 & $>99.95$ \\
\hline \multirow[t]{4}{*}{1} & \multirow[t]{4}{*}{ 3Z-SMB } & 7.5 & 0.45 & 0.65 & $\mathrm{x}$ & & 76.8 & 918.5 & $>99.90$ \\
\hline & & 7.5 & 0.58 & 0.80 & & $\mathrm{x}$ & 99.3 & 195.6 & 100 \\
\hline & & 20 & 0.10 & 0.65 & $\mathrm{x}$ & & 647.4 & 91.9 & $>99.95$ \\
\hline & & 20 & 0.58 & 0.77 & & $\mathrm{x}$ & 264.8 & 72.3 & 100 \\
\hline \multirow[t]{2}{*}{$2^{\mathrm{b}}$} & \multirow[t]{2}{*}{ 4Z-SMB } & 7.5 & 0.2 & 1.2 & $\mathrm{x}$ & & 515 & 450 & $>99.50$ \\
\hline & & 7.5 & 1.0 & 1.6 & & $\mathrm{x}$ & 395 & 560 & $>99.50$ \\
\hline
\end{tabular}

For case study $1(\mathrm{CS} 1)$ the regeneration flow rate ratios of the SMB unit were fixed to $m_{\mathrm{I}}=0.8$ and $m_{\mathrm{IV}}=$ 0.3 for the $4 \mathrm{Z}$ configurations. The batch version was operated with a flow rate of $Q_{\text {batch }}=0.5 \mathrm{~mL} / \mathrm{min}$. The flow rate ratios for CS2 are estimated to be $m_{\mathrm{I}} \approx 1.5$ and $m_{\mathrm{IV}} \approx 1$

${ }^{a}$ The values for the batch chromatography process of CS1 were taken from Wrzosek et al. (2018).

${ }^{\mathrm{b}}$ The values required for the CS2 are estimated from Figs. 5 and 6 in Fuereder et al. (2016) 
far left from the separation area of a non-integrated SMB process. This results in an overall productivity for the first eluting E1 of $486 \mathrm{~g} / \mathrm{kg} /$ day, which significantly exceeds the productivity for E2 of $199 \mathrm{~g} / \mathrm{kg} /$ day (Fig. 5f).

\subsection{Batch and 4Z-SMB chromatography (CS1)}

In Wrzosek et al. (2018) the coupling of single column enantioselective batch chromatography and racemization is analysed in detail. One main advantage of simple batch elution using repetitive injections is the reduced operational complexity. However, in batch chromatography the mixture is only injected in pulses and therefore a rather low average feed concentration is applied, compared to SMB operation. For both enantiomers of CS1, only low average feed concentrations (Eq. (8)) of $\bar{c}_{i, \mathrm{~F}}=1.1 \mathrm{~g} / \mathrm{L}$ and $\bar{c}_{i, \mathrm{~F}}=0.9 \mathrm{~g} / \mathrm{L}$ could be reached after optimizing the cycle times and injection dosages $\left(c_{i, \mathrm{~F}}=20 \mathrm{~g} / \mathrm{L}, V_{i, \text { inj }}=100 \mu \mathrm{L}\right)$. The resulting productivities (Eq. (43)) were $P R_{1}=209 \mathrm{~g} / \mathrm{kg} / \mathrm{d}$ for E1 and $P R_{2}=161 \mathrm{~g} / \mathrm{kg} / \mathrm{d}$ for E2 and solvent consumptions (Eq. (44)) of $S C_{1}=888 \mathrm{~kg} / \mathrm{L}$ and $S C_{2}=1150 \mathrm{~kg} / \mathrm{L}$ for E1 and E2, respectively.

In Fig. 6, a comparison between integrating a single batch column and a $4 \mathrm{Z}-\mathrm{SMB}$ unit with racemization is shown. For the same high feed concentrations especially the production of E1 is more productive in the multi column configuration, as more throughput can be generated. Moreover, the solvent consumption is significantly higher for batch chromatography.

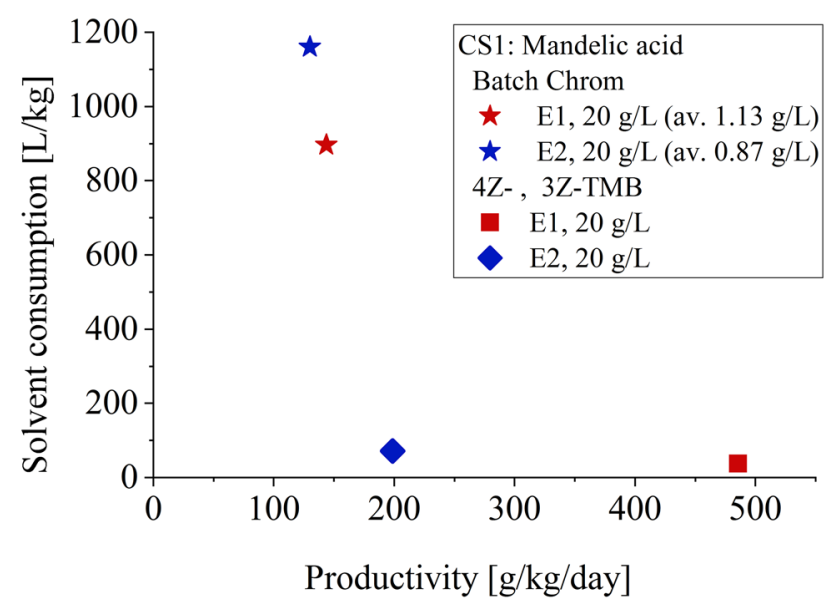

Fig. 6 Comparison of coupled systems for CS1 with a single batch chromatographic unit (Wrzosek et al. 2018) and a 4Z-SMB unit with the same racemic feed tank concentration of $c_{i, \mathrm{~F}}=20 \mathrm{~g} / \mathrm{L}$ in terms of productivity and solvent consumption for the options either of the enantiomers is targeted

\subsection{Comparison of CS1 and CS2}

It is well known that the selectivity of chromatographic separation of the enantiomers, as well as the course of the adsorption isotherms, are of large importance. When comparing the selectivities (Eq. (13)) of separating the mandelic acid enantiomers ( $\mathrm{CS} 1)$ of $\alpha_{c, \mathrm{CS} 1}=2.44$ and methionine enantiomers (CS2) of $\alpha_{c, \mathrm{CS} 2}=2.58$, they appear to have a similar ratio. However, due to the different shapes of the isotherms, for higher concentrations the adsorption strength of the two enantiomers from CS2 differs more than those of the enantiomers of CS1 (Fig. 3). Consequently, the separation of CS2 can be performed with a larger difference of $m_{\mathrm{III}}-m_{\mathrm{II}}$ and thus with a higher feed stream, which has a direct impact on productivity.

In Fig. 7, the productivities and solvent consumptions of both case studies are compared using the integrated closedloop 4Z-SMB setup. The process performance data for CS2 was taken from Fuereder et al. (2016) and is listed in Table 2. For the maximum processable feed concentration of $c_{\mathrm{i}, \mathrm{F}}=7.5 \mathrm{~g} / \mathrm{L}\left(c_{\mathrm{tot}, \mathrm{F}}=15 \mathrm{~g} / \mathrm{L}\right)$ the productions of both methionine enantiomers (CS2) exceed, the productivities of mandelic acid enantiomers (CS1) at the same feed concentration. However, when exploiting the potential of using a higher feed concentration of $c_{\mathrm{i}, \mathrm{F}}=20 \mathrm{~g} / \mathrm{L}$ in CS1 (close to the solubility limit), a productivity for E1 of $486 \mathrm{~g} / \mathrm{kg} /$ day can be achieved, which is similar to that of CS2. Furthermore, the increased feed concentration in CS1 results in a significantly decrease in solvent consumption, offering a higher product concentration.

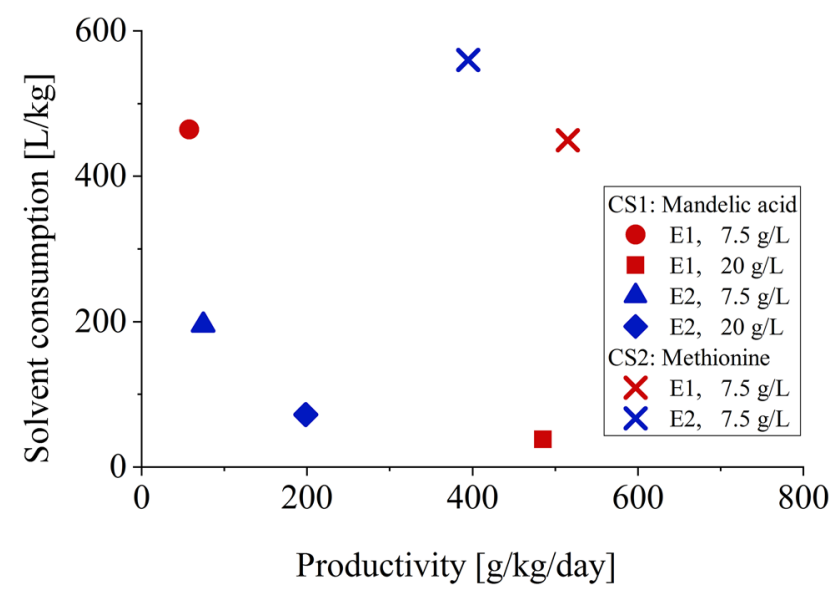

Fig. 7 Comparison of solvent consumption and productivity of CS1 and CS2 for a process with an integrated closed-loop 4Z-SMB unit in terms of productivity and solvent consumption for the options either of the enantiomers is targeted 


\subsection{Applying an integrated open-loop 3Z-SMB unit}

As discussed in Sect. 2, the closed-loop 4Z-SMB unit can easily be simplified and run in an open-loop 3Z-SMB configuration by removing the fourth zone. The effect on the process performance for the enantiomers of CS1 is depicted in Fig. 8. Analog to Fig. 5, the results of scanning the $m_{\mathrm{II}}-m_{\mathrm{III}}$-area for a fixed flow rate ratio in the first zone of $m_{\mathrm{I}}=0.8$ is displayed. The operating points corresponding to the highest productivity and lowest solvent consumption are depicted by asterisks and plotted in Fig. 9, along with the respective less favourable 4Z-SMB results.

Figure 8, in comparison to Fig. 5, also shows that the available operation window for pure target enantiomer production remains unaffected by the removal of the fourth regeneration zone. By sparing one zone, or $25 \%$ of the stationary phase, the process productivity increases by $33 \%$ for both enantiomers and all concentrations. This affects in particular the already effective raffinate production (Fig. 1a) for $c_{i, \mathrm{~F}}=20 \mathrm{~g} / \mathrm{L}$, increasing its value from 486 to $647 \mathrm{~g} / \mathrm{kg} / \mathrm{day}$. On the other hand, the $3 \mathrm{Z}$ open-loop configuration increases the solvent consumption and causes a more diluted product. It should be noted that, for the

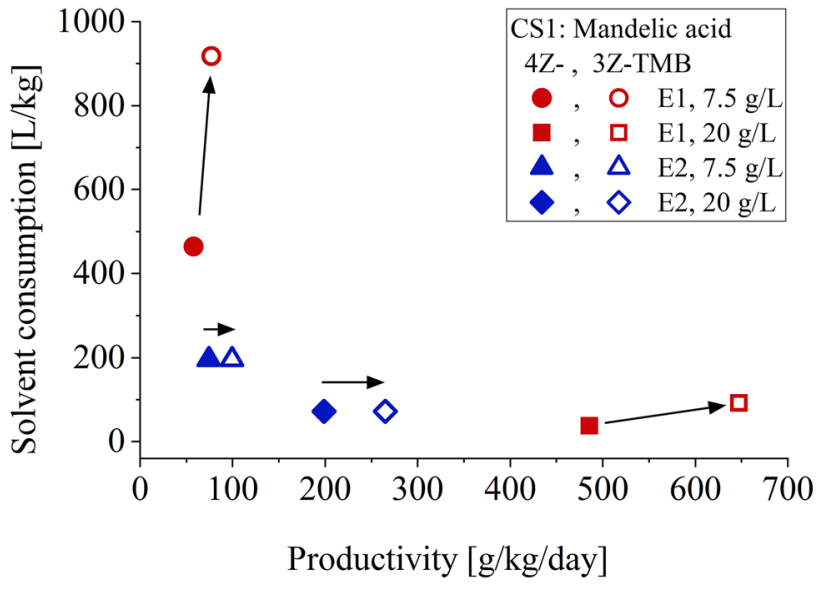

Fig. 9 Comparison of solvent consumption and productivity for 4Z-, 3Z-SMB for CS1 with $c_{i, \mathrm{~F}}=7.5$ and $20 \mathrm{~g} / \mathrm{L}$, batch chromatography for $20 \mathrm{~g} / \mathrm{L}$ in terms of productivity and solvent consumption for the option either of the enantiomers is targeted

closed-loop 4Z-SMB separation, the fronting behaviour of E1 requires a small flow rate ratio $m_{\mathrm{IV}}$ regardless. Thus,
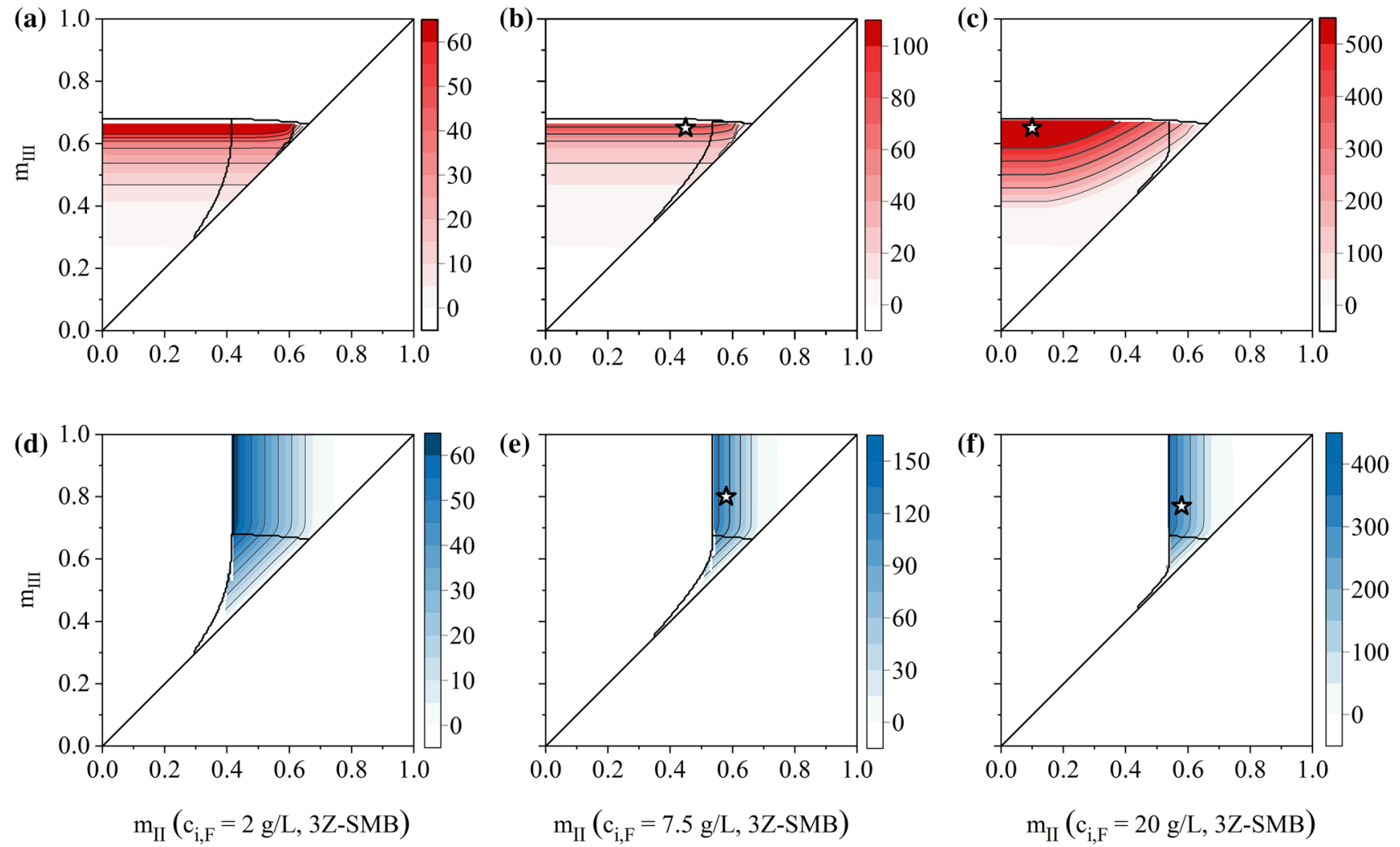

Fig. 8 Color-coded productivity in $\mathrm{g} / \mathrm{kg} /$ day of the coupled process for $\mathrm{E} 1$ and $\mathrm{E} 2$ of CS1 within the separation zones A1 and A2, respectively $\left(P U R_{\text {target }}=99.5 \%\right.$, compare with Fig. 4$)$. The separation unit was operated in a closed-loop 4Z-TMB with fresh feed concentrations of $c_{i, \mathrm{~F}}=2,7.5$ and $20 \mathrm{~g} / \mathrm{L}$ for a conventional open-loop 3Z-TMB with flow rates of the regeneration zone of $m_{\mathrm{I}}=0.8$ and $m_{\mathrm{IV}}=0.3$. $\mathbf{a}-\mathbf{c}$ regions of pure raffinate, $\mathbf{d}-\mathbf{f}$ regions of pure extract. Asterisked points are marked in Figs. 9 and 10 
the mentioned disadvantage of the 3Z-SMB configuration is rather small for CS1.

The process performance of 3Z-SMB intended to provide E2 (Fig. 1b) is affected differently by the removal of zone IV. The productivity of E2 is also higher than the performance including the 4Z-SMB configuration but, the absolute gain is lower compared to E1. In contrast to the diluted raffinate flow rate for the production of E1, the extract flow rate, $Q_{\mathrm{E}}$, is unaffected by the new configuration. Therefore, the target E2 is not diluted. In terms of solvent consumption, this means no negative effect of the removed recovery zone. The extra solvent eluting with the distomer in the recycling stream can be recovered by adapting the solvent removal unit, which is already integrated in the process. Thus, the solvent consumption required to produce $\mathrm{E} 2$ with an $3 Z-\mathrm{SMB}$ remains the same as for the $4 \mathrm{Z}-\mathrm{SMB}$ configuration. No negative effect is caused by the removal of the recovery zone. A significant advantage of this configuration for producing highly pure E2 is the beneficial effect that E1 can no longer contaminate the product extract stream via zone I.

\subsection{High process performance for production of E1}

Figure 10 provides a summary of the essential results achieved. It presents a comparison of the productivities and solvent consumptions for the three chromatographic configurations and two case studies considered. Independent of the adsorption behaviour and the process configurations, the highest productivities were always achieved for the less retained enantiomer E1, which is eluting at the raffinate port (Fig. 1a). This confirms common knowledge in preparative chromatography (Guiochon et al. 2006). Thus, this should be considered for the design of new SMB processes, e.g. by changing the eluent for a reversal of the enantiomeric elution order as proposed by Okamoto and Nakazawa (1991).

\section{Conclusions}

An effective process concept for the provision of pure enantiomers with high yield is investigated in this work. The key idea is the combination of enantioselective chromatography with racemization to efficiently exploit the unwanted enantiomer of a feed with racemic composition. Recycling this enantiomer, after performing racemization and solvent removal steps, alters and expands the operating region of the chromatographic separation process. Conventional single column batch chromatography and two simulated moving bed (SMB) multi-column configurations were investigated theoretically, assuming complete racemization of the distomer. The considered SMB units are (a) a classical closed-loop four zone (4Z) and (b) an openloop three zone (3Z) SMB separation process without a solvent regeneration zone.

The SMB configurations provide higher total productivities and lower solvent consumptions compared to single column batch chromatography. In a direct comparison, the 3Z-SMB outperformed the conventional $4 Z$ setup. Besides being simpler, this configuration can save $25 \%$ of the stationary phase without reducing throughput and yield, leading to a productivity enhancement of $33 \%$. When focusing on the stronger retained enantiomer as the target and recycling the raffinate, unlike in a non-integrated SMB unit,

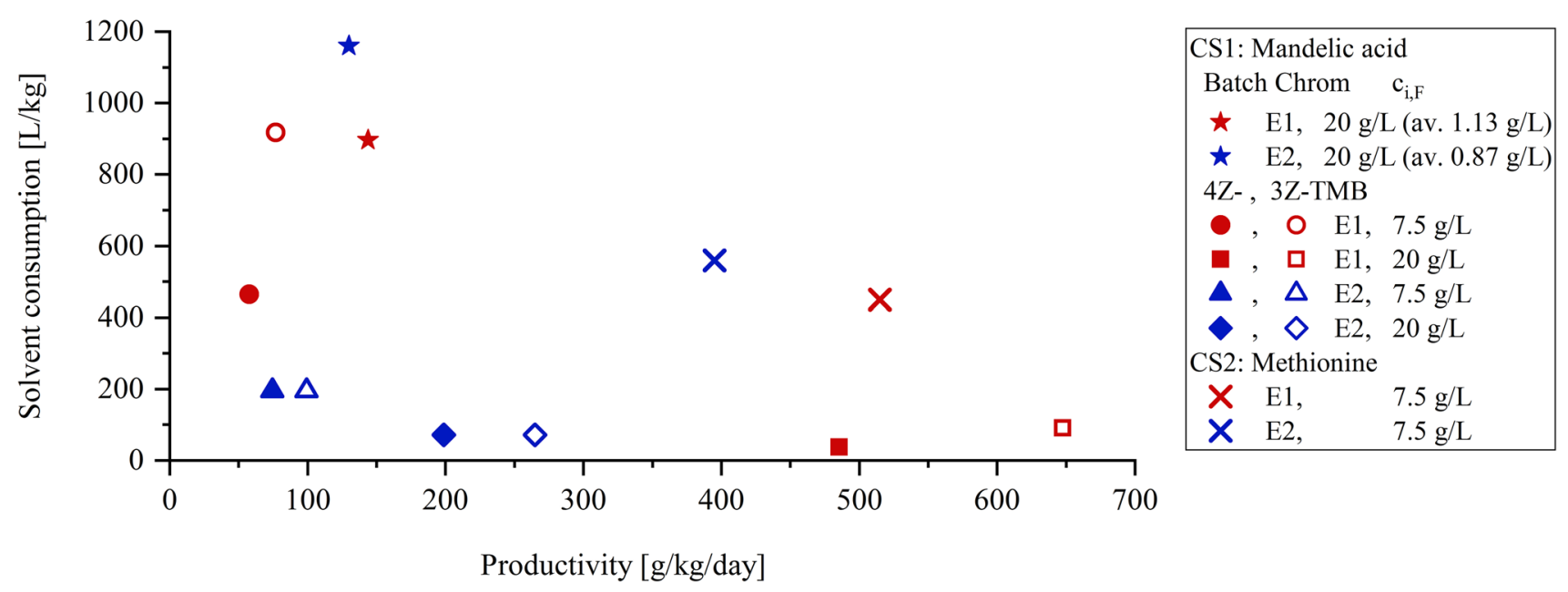

Fig. 10 Comparison of the solvent consumptions and productivities for 4Z-, 3Z-SMB with a feed concentration of $c_{i, \mathrm{~F}}=7.5$ and $20 \mathrm{~g} / \mathrm{L}$ (CS1), batch chromatography for $c_{i, \mathrm{~F}}=20 \mathrm{~g} / \mathrm{L}(\mathrm{CS} 2)$ and 4Z-SMB

with a feed concentration of $c_{i, \mathrm{~F}}=7.5 \mathrm{~g} / \mathrm{L}$ for CS2 in terms of productivity and solvent consumption for the options either of the enantiomers is targeted 
Table 3 Nomenclature

\begin{tabular}{|c|c|c|}
\hline Symbol & Variables & Units \\
\hline$c_{i}$ & Conc. of component $i$ in liquid phase & $g / L$ \\
\hline$q_{i}$ & Loading of component $i$ onto stationary phase & $\mathrm{g} / \mathrm{L}$ \\
\hline Symbol & Parameters & Units \\
\hline$\alpha_{\mathrm{c}}$ & Chromatographic separation factor & - \\
\hline$\alpha_{\mathrm{SR}}$ & Split factor of solvent removal unit & - \\
\hline$\epsilon_{\mathrm{t}, \mathrm{c}}$ & Porosity of chromatographic column & - \\
\hline$v_{i}$ & Stoichiometric coefficient & - \\
\hline$b_{i, 1}$ & Adsorption isotherm coefficient & $\mathrm{L} / \mathrm{g}$ \\
\hline$b_{i, 2}$ & Adsorption isotherm coefficient & $\mathrm{L}^{2} / \mathrm{g}^{2}$ \\
\hline$D_{\text {app }}$ & Apparent dispersion & $\mathrm{m} / \mathrm{s}^{2}$ \\
\hline$F_{\mathrm{c}}$ & Phase ratio & - \\
\hline HETP & Height of an equivalent theor. plate & - \\
\hline$K_{i}$ & Henry constant of component $i$ & - \\
\hline$L_{\mathrm{c}}$ & Column length & $\mathrm{m}$ \\
\hline$m_{\mathrm{z}}$ & Dimensionless flow rate of zone $\mathrm{z}$ & - \\
\hline$\dot{m}_{i}$ & Through put & $\mathrm{g} / \mathrm{d}$ \\
\hline$N$ & Number of components & - \\
\hline$N_{\text {col }}$ & Number of columns & - \\
\hline$N_{\mathrm{p}}$ & Number of theoretical plates & - \\
\hline$P R_{i}^{*}$ & Productivity of component i & $\mathrm{g} / \mathrm{L} / \mathrm{d}$ \\
\hline$P R_{i}$ & Productivity of component i & $\mathrm{g} / \mathrm{kg} / \mathrm{d}$ \\
\hline$P U R_{i}$ & Purity of component i & $\%$ \\
\hline$Q_{\text {ext }}$ & Inlet and outlet of liquid phase & L/day \\
\hline$Q_{\mathrm{s}}$ & Flow rate of solid phase & $\mathrm{mL} / \mathrm{min}$ \\
\hline$Q_{\mathrm{z}}$ & Flow rate of liquid phase in zone $\mathrm{z}$ & L/day \\
\hline$q_{\mathrm{s}}$ & Saturation capacity & $\mathrm{g} / \mathrm{L}$ \\
\hline$R E C_{\mathrm{SR}}$ & Recovered ratio & $\%$ \\
\hline$S C_{i}$ & Solvent consumption & $\mathrm{kg} / \mathrm{L}$ \\
\hline$t$ & Time variable & $\min$ \\
\hline$\Delta t_{\mathrm{i}, \mathrm{cyc}}$ & Cycle time of component $\mathrm{i}$ & $\min$ \\
\hline$u_{\mathrm{z}}$ & Interstitial velocity of liquid phase & $\mathrm{m} / \mathrm{min}$ \\
\hline$u_{\mathrm{s}}$ & Velocity of solid phase & $\mathrm{m} / \mathrm{min}$ \\
\hline$V_{\mathrm{c}}$ & Column volume & $\mathrm{mL}$ \\
\hline$V_{\text {cell }}$ & Single cell volume & $\mathrm{mL}$ \\
\hline$V_{i, \text { inj }}$ & Injection volume & $\mathrm{mL}$ \\
\hline$V_{\mathrm{SR}}$ & Volume of solvent removal unit & $\mathrm{mL}$ \\
\hline$V_{\text {tank,D }}$ & Desorbent tank volume & $\mathrm{mL}$ \\
\hline$V_{\text {tank,F }}$ & Feed tank volume & $\mathrm{mL}$ \\
\hline$x$ & Space variable & $\mathrm{m}$ \\
\hline$Y_{i}$ & Process yield & $\%$ \\
\hline Symbol & Indices & Range \\
\hline$z$ & Cone number & $\mathrm{I}, \ldots, \mathrm{IV}$ \\
\hline$i$ & Number of component & 1,2 \\
\hline $\mathrm{D}$ & Desorbent inlet & \\
\hline $\mathrm{D}, 0$ & Fresh desorbent & \\
\hline E & Extract port & \\
\hline $\mathrm{F}$ & Feed inlet & \\
\hline $\mathrm{F}, 0$ & Fresh feed inlet & \\
\hline
\end{tabular}


Table 3 (continued)

\begin{tabular}{ll}
\hline Symbol & Indices \\
\hline $\mathrm{R}$ & Raffinate port \\
$\mathrm{rac}$ & Racemate port \\
rec & Recycled stream \\
tot & Component $1+2$ \\
perm & Permeate stream \\
\hline
\end{tabular}

the 3Z-SMB unit with racemization requires no additional solvent compared to the classical $4 \mathrm{Z}$ configuration.

A comparison between two chiral systems revealed that the most important aspects to achieve high productivities are (i) highly selective stationary phases, and (ii) exploitable high feed concentrations, which are limited by solubilities in the mobile phase. Also, the chromatographic separation system should preferably be designed for less retention of the target enantiomer in order to elute it at the raffinate outlet (Table 3).

Further work is required to perform an optimization of the entire flowsheet, which is difficult due to the large number of degrees of freedom, including the racemization and solvent removal steps, and must be accomplished target compound specific.

Acknowledgements Open access funding provided by Projekt DEAL.

\section{Compliance with ethical standards}

Conflict of interest The authors declare that they have no conflict of interest.

Open Access This article is licensed under a Creative Commons Attribution 4.0 International License, which permits use, sharing, adaptation, distribution and reproduction in any medium or format, as long as you give appropriate credit to the original author(s) and the source, provide a link to the Creative Commons licence, and indicate if changes were made. The images or other third party material in this article are included in the article's Creative Commons licence, unless indicated otherwise in a credit line to the material. If material is not included in the article's Creative Commons licence and your intended use is not permitted by statutory regulation or exceeds the permitted use, you will need to obtain permission directly from the copyright holder. To view a copy of this licence, visit http://creativecommons.org/licenses/by/4.0/.

\section{References}

Bechtold, M., Makart, S., Heinemann, M., Panke, S.: Integrated operation of continuous chromatography and biotransformations for the generic high yield production of fine chemicals. J. Biotechnol. 124(1), 146-162 (2006)

Broughton, D.B., Gerhold, C.G.: Continuous sorption process employing fixed bed of sorbent and moving inlets and outlets. US Patent $2,985,589(1961)$
Femmer, C., Bechtold, M., Roberts, T.M., Panke, S.: Exploiting racemases. Appl. Microbiol. Biotechnol. 100(17), 7423-7436 (2016)

Franco, P., Senso, A., Oliveros, L., Minguillón, C.: Covalently bonded polysaccharide derivatives as chiral stationary phases in highperformance liquid chromatography. J. Chromatogr. A 906(1-2), $155-170(2001)$

Francotte, E.R.: Enantioselective chromatography as a powerful alternative for the preparation of drug enantiomers. J. Chromatogr. A 906(1-2), 379-397 (2001)

Fuereder, M., Majeed, I.N., Panke, S., Bechtold, M.: Model-based identification of optimal operating conditions for amino acid simulated moving bed enantioseparation using a macrocyclic glycopeptide stationary phase. J. Chromatogr. A 1346, 34-42 (2014)

Fuereder, M., Femmer, C., Storti, G., Panke, S., Bechtold, M.: Integration of simulated moving bed chromatography and enzymatic racemization for the production of single enantiomers. Chem. Eng. Sci. 152, 649-662 (2016)

Guiochon, G., Felinger, A., Shirazi, D.G.: Fundamentals of Preparative and Nonlinear Chromatography. Academic Press, New York (2006)

Hashimoto, K., Adachi, S., Noujima, H., Ueda, Y.: A new process combining adsorption and enzyme reaction for producing higherfructose syrup. Biotechnol. Bioeng. 25(10), 2371-2393 (1983)

Ilić, M., Flockerzi, D., Seidel-Morgenstern, A.: A thermodynamically consistent explicit competitive adsorption isotherm model based on second-order single component behaviour. J. Chromatogr. A 1217(14), 2132-2137 (2010)

Lorenz, H., Seidel-Morgenstern, A.: Processes to separate enantiomers. Angew. Chem. Int. Ed. 53(5), 1218-1250 (2014)

Martín-Matute, B., Bäckvall, J.E.: Dynamic kinetic resolution catalyzed by enzymes and metals. Curr. Opin. Chem. Biol. 11(2), 226-232 (2007)

Mazzotti, M., Storti, G., Morbidelli, M.: Optimal operation of simulated moving bed units for nonlinear chromatographic separations. J. Chromatogr. A 769(1), 3-24 (1997)

Nimmig, S., Kaspereit, M.: Continuous production of single enantiomers at high yields by coupling single column chromatography, racemization, and nanofiltration. Chem. Eng. Process. 67, 89-98 (2013)

Okamoto, M., Nakazawa, H.: Reversal of elution order during direct enantiomeric separation of pyriproxyfen on a cellulose-based chiral stationary phase. J. Chromatogr. A 588(1-2), 177-180 (1991)

Palacios, J.G., Kaspereit, M., Kienle, A.: Integrated simulated moving bed processes for production of single enantiomers. Chem. Eng. Technol. 34(5), 688-698 (2011)

Paredes, G., Abel, S., Mazzotti, M., Morbidelli, M., Stadler, J.: Analysis of a simulated moving bed operation for three-fraction separations (3f-smb). Ind. Eng. Chem. Res. 43(19), 6157-6167 (2004)

Radkov, A.D., Moe, L.A.: Amino acid racemization in pseudomonas putida kt2440. J. Bacteriol. 195(22), 5016-5024 (2013)

Rodrigues, A.: Simulated Moving Bed Technology: Principles, Design and Process Applications. Butterworth-Heinemann, Oxford (2015) 
Schmidt-Traub, H., Schulte, M., Seidel-Morgenstern, A.: Preparative Chromatography. Wiley, Weinheim (2012)

Sreedhar, B., Kawajiri, Y.: Multi-column chromatographic process development using simulated moving bed superstructure and simultaneous optimization-model correction framework. Chem. Eng. Sci. 116, 428-441 (2014)

Swernath, S., Kaspereit, M., Kienle, A.: Coupled continuous chromatography and racemization processes for the production of pure enantiomers. Chem. Eng. Technol. 37(4), 643-651 (2014)

von Langermann, J., Kaspereit, M., Shakeri, M., Lorenz, H., Hedberg, M., Jones, M.J., Larson, K., Herschend, B., Arnell, R., Temmel, E., et al.: Design of an integrated process of chromatography, crystallization and racemization for the resolution of 2, 6-pipecoloxylidide (ppx). Org. Process Res. Dev. 16(2), 343-352 (2012)

Wagner, N., Fuereder, M., Bosshart, A., Panke, S., Bechtold, M.: Practical aspects of integrated operation of biotransformation and smb separation for fine chemical synthesis. Org. Process Res. Dev. 16(2), 323-330 (2011)

Wrzosek, K., García Rivera, M.A., Bettenbrock, K., Seidel-Morgenstern, A.: Racemization of undesired enantiomers: Immobilization of mandelate racemase and application in a fixed bed reactor. Biotechnol. J. 11(4), 453-463 (2016)

Wrzosek, K., Harriehausen, I., Seidel-Morgenstern, A.: Combination of enantioselective preparative chromatography and racemization: experimental demonstration and model-based process optimization. Org. Process Res. Dev. 22(12), 1761-1771 (2018)

Würges, K., Petrusevska, K., Serci, S., Wilhelm, S., Wandrey, C., Seidel-Morgenstern, A., Elsner, M.P., Lütz, S.: Enzyme-assisted physicochemical enantioseparation processes: Part I. Production and characterization of a recombinant amino acid racemase. J. Mol. Catal. B 58(1-4), 10-16 (2009)

Publisher's Note Springer Nature remains neutral with regard to jurisdictional claims in published maps and institutional affiliations. 